\title{
Introduction: a jurisprudence of environmental governance?
}

\section{Paul Martin and Amanda Kennedy}

The history of science shows that the evolution of scholarly investigation follows two lines of development. The first is that innovations undergo a transformation from relatively low efficiency to higher efficiency as the discovery is refined and applied; implementation skill is gained through experience; and incremental inventions that improve on the original are brought to bear. ${ }^{1}$ This phenomenon has been observed in many fields of knowledge. It is well illustrated by the trajectories of computer technology, psychological science, transport methods and in almost any other area of human endeavour where disciplined and purposeful development is applied. ${ }^{2}$

The second evolutionary pattern is that in most fields deepening of knowledge leads to differentiation into specialisations. This is illustrated by the physical sciences. Prior to the Scientific Enlightenment, religion, philosophy and science were intermixed. Gradually, subjective elements were excised from what was characterised as legitimate science. Philosophy, religion and science became distinct. These investigations evolved along different paths, as scholars and practitioners tackled increasingly specialist challenges. In science, what are now called chemistry and physics were originally intermixed, but gradually developed distinct epistemology and methodologies, as researchers pursued more specialised knowledge. Within physics, for example, there are epistemological differences between nuclear physics, planetary physics, and many esoteric and applied pursuits of principles and methods of this science. Over time sub-fields proliferate and become more knowledgeintense. They interact less with the parent field from which they evolve or

1 David Teece (1986).

2 Robert Schaller (1997). 
with their sibling specialisations. Opportunities for creative recombination do not disappear, but become notable as boundary-spanning instances (particularly illustrated by Linus Pauling's two Nobel Prizes). ${ }^{3}$

The phenomena of evolution towards greater efficiency and differentiation are not only present in physical and experimental sciences. The evolution of economics into its specialisations such as microeconomics, behavioural economics, principal-agency economics and transaction cost economics is a useful illustration. ${ }^{4}$ Similar patterns can be seen in psychology, sociology and other social sciences. ${ }^{5}$ The same dynamics exist with the scholarly investigation of the science and philosophy of law ('jurisprudence').

These evolutionary patterns are the result of two forces. The first is adaptation to external challenges (such as community expectations of better performance from the products of scholarship), the infusion of knowledge from other fields, new technologies, novel methods of investigation, or a change to the broader context. The impact of climate change threats upon the scholarship and application science of mathematics, economics, ecological science, hydrology, coastal morphology, and many other fields illustrates the creative scholarly response to such external pressures. The need for useful knowledge, combined with infusions of methods from other disciplines, has driven investigation and discovery. The second driver is self-generating change from within a community of scholars, termed 'autopoetic' development. ${ }^{6}$ Driven by curiosity, peer competition and collaboration, academic entrepreneurship and other internal causes (individual or collective), scholars self-generate questions and methods that feed innovations in epistemology.

In the evolution of environmental law these patterns and drivers of evolution can be seen. Environmental law as a distinct field of scholarship and practice was a response to external forces, including developments in ecological science and increasing public awareness, which drove political responses to these pressures. These external stimuli intersected with the sensibilities of lawyers, driving the creativity that has fostered many legal innovations. The subject matter of environmental law

\footnotetext{
3 Nobelprize.org, 'Linus Pauling - Facts' (2014).

4 Brian Loasby (2002).

5 Schultz and Schultz (2011); David Ashley and David Orenstein (2005); Kuper and Kuper (1996); Solomon and Higgins (1996).

6 Luhmann (1995).
} 
has expanded to address many attributes of the natural world, diverse human interests and many ecosystem types. ${ }^{7}$

An important milestone of scholarly evolution is when the discipline identifies that a particular aspect of its work has become so specialist that it is worth recognising this cohort of investigators as pursuing distinct epistemologies. This book proposes that the investigation of the applied effectiveness of environmental law as a component of environmental governance systems is now deserving of that identification. The chapters in this volume highlight the distinctiveness of enquiries into the effective implementation of environmental law instruments. They suggest some of the unique research questions that might be pursued by a cohort of investigators pursuing a jurisprudence of the effectiveness of environmental law.

\section{JURISPRUDENCE AND THE EVOLUTION OF ENVIRONMENTAL LAW}

Modern environmental law scholarship pursues three types of enquiry that have distinct epistemologies. Scholars pursue different questions, use different methods and propose radically different types of solutions to environmental and social justice issues. They use varied theoretical frameworks to inform investigation within their specialisation. Given the nature of law, there is no hierarchy of importance between the subdisciplines. The law is unique among public policy and social disciplines in integration of values and philosophy with the creation, interpretation and application of legal instruments, whilst needing to grapple with pragmatic challenges of improving the effectiveness, efficiency and fairness of natural resource governance. ${ }^{8}$ Most other disciplines deal only with some aspects of the total challenge, and none have the same direct pathway to application that is a characteristic of the law.

These intersecting specialisations within environmental law scholarship are:

(1) 'Philosophical' jurisprudence. This incorporates a substantial amount of political argumentation. It is concerned largely with shaping the goals of environmental law and refining the values that should be incorporated in legal instruments. The emergence of

7 Pūraitè (2012); Tarlock (2010); Tarlock (2003); Lazarus (1996); Winter (1989).

8 See Martin and Craig, Chapter 1 below. 
distinct theories of 'environmental jurisprudence' and environmental social justice illustrates evolution within this specialisation. ${ }^{9}$

(2) 'Instrumental' scholarship, focused upon doctrinal enquiry and legal instruments. The instruments upon which attention has been focused are judgements and statutes (viz. instruments of government). Increasingly private instruments such as market instruments and industry codes and standards are replacing or supplementing public instruments, though legal scholarship has been slow to come to grips with this development. Most mainstream environmental law scholarship is instrumentally focused.

(3) 'Operational' (or 'applied', or 'institutional') investigation, concerned with organisational structures and implementation. The focus is upon understanding and improving the efficiency, effectiveness, and fairness of instruments (measured partly against philosophical values). Effectiveness is concerned with moving law 'off the page', and thus this type of legal scholarship is more closely aligned to the empirical sciences than are philosophic or instrumental specialisations. However, because the law is concerned with applying social values, this jurisprudence must integrate aspects of both science and philosophy.

This book is designed to focus attention upon operational effectiveness and reform as a specialist field of jurisprudential enquiry. Research on implementation concerns phenomena observable in the real world, and this type of scholarship explores how these might be brought into alignment with phenomena envisaged in the idealised world proposed through legal philosophy, or the objectives that underpin legal instruments. The authors of the chapters in this book point to the uniqueness of the scholarly and practical issues that arise when the concern is the operational effectiveness of environmental law. Together the chapters allow insight into the real-world challenges and opportunities for innovation in the implementation of public and private legal arrangements. These arrangements are intended to advance the effective stewardship of natural resources, and improve fairness in the distribution of the costs and benefits of using and conserving the natural environment.

The idea for this book took root in 2012, with a proposal to the Research Committee of the IUCN Academy of Environmental Law for a workshop on implementation of environmental law. This took place in

9 Westbrook (1993); Burdon (2012); Baber and Bartlett (2009); Riddell (2014) 21. 
2013 at the Academy's annual Colloquium. More recent developments discussed below are indicative of a zeitgeist. This book is intended to respond to that movement by suggesting directions for scholarship that can assist in responding to the newly identified imperative for effectively implemented legal arrangements.

\section{GOVERNANCE SYSTEMS OR LEGAL INSTRUMENTS?}

A fundamental distinction in the investigation of effective implementation is between research of legal instruments and the investigation of systems of governance. The chapters variously deal with legal instrumental issues, public law and private contract, non-government 'voluntary' self-regulation, economic instruments, collaborative networks, power relationships in consultation processes, the effects of social and political dynamics, and many other causes of the effectiveness (or otherwise) of legal governance arrangements. Their suggestions of ways to improve effectiveness point to actions as diverse as the redesign of regulatory and international instruments, improving private contracts or market standards, better coordination of bureaucracies, new collaborative strategies, more sophisticated knowledge development and many other behavioural and organisational interventions. The net effect is to make it clear that diagnosis of effectiveness requires consideration of a complex mix of legal and non-legal matters, human and organisational behaviours, the multi-faceted contexts within which instruments operate, and pragmatic considerations such as economic resources and human capacity. In moving from a jurisprudence of instruments to a jurisprudence of implementation, there is a change of focus away from instruments towards the total system of governance where the law is a central, but not the overriding, consideration.

Governance is systemic. The IUCN World Conservation Congress defines governance as the '... interactions among structures, processes and traditions that determine how power and responsibilities are exercised, how decisions are taken, and how citizens or other stakeholders have their say in the management of natural resources - including biodiversity conservation' (IUCN WCC Resolution 3.012). It involves many participants including government officials, traditional authorities, self-government as well as non-government actors. It relies upon norms that may be formal or informal, and upon implementation organisations and structures. Governance systems vary between communities, and they constantly evolve. In some circumstances, there are intersecting or 
competing governance systems at work within or between jurisdictions. Thus, nation-state governance arrangements often intersect with private sector approaches including voluntary or supply chain codes; or with traditional and indigenous norms for conserving and using the natural world. For these reasons, the jurisprudence of effective implementation of environmental law requires novel methods to generate different types of insight to those sought from the other streams of environmental jurisprudence.

\section{WHICH RULES ARE RELEVANT?}

A central aspect of governance is the rules (or norms) which are at the heart of the system, but this raises the questions: 'whose rules' and 'what rules'? There are many rules that control how societies interact with the natural environment, how natural resources are accessed, used and transformed, conserved and how the cost and benefits from resources are distributed. This includes rules related to:

- The quality of natural resources such as the atmosphere, water, soil, climate;

- How all types of natural resources are allocated or used;

- Access to and benefit-sharing related to biodiversity;

- Energy generation; and

- All other activities with the potential for significant environmental impact.

Whilst legal judgments and regulations created by the nation-state and the community of states are fundamental to environmental law, private citizens (through agreements and self-government) also create rights and responsibilities to the natural world. The chapters in this volume discuss rules arising from international environmental conventions (e.g. bilateral or multilateral environmental agreements), national constitutions, statutes, judgments and rulings or administrative instruments. In the case of non-state governance the authors reference 'voluntary' collective arrangements and corporate self-standards. Whilst none of the chapters in this book focus upon traditional peoples' custodianship systems, the importance of customary law and other social norms must not be discounted as increasingly important in the scholarship of legal natural resource governance.

A taxonomy of rule types highlights various sources of authority, and that even non-state rules can be recognised by the nation-state in many 
ways. A listing of rule categories (based upon an unpublished methodology for the evaluation of the effectiveness of environmental law) shows the many different sources of natural resource institutions: ${ }^{10}$

(a) State-created formal rules, including constitutions, statutes, regulations, and administrative rules and plans.

(b) State-based judicial rules, which include judgments of courts and tribunals, and binding rulings of quasi-judicial authorities or agents of government.

(c) State-supported private (broadly consensual) rules, with the most common form of support for consensual arrangements being contract and property rights.

(d) International, bilateral, or multilateral treaties, conventions, and agreements. International arrangements have varying degrees of formal acceptance by nation states and communities.

(e) Spanning both nation-state law and international law are legal norms that have the status of being self-evident principles of law within a jurisdiction or in international jurisprudence, such as acceptance of the rule of law.

(f) Rules emerging from communities (in particular indigenous communities), often referred to as 'customary law'.

State-based formal rules, widely ratified international conventions, and principles endorsed by courts (such as equality before the law) are the most legally conventional. Un-documented norms and rules, including traditional rules for natural resource governance, vary in legal status but it is not legal status alone that determines their effectiveness in practice. The chapters illustrate that natural resources law consists of far more than rules. The quality and integrity of the arrangements for creating and implementing rules (institutions and processes) are critical. Understanding effectiveness in practice requires consideration of the quality, integrity, capacities and performance of political, legal, administrative and judicial bodies; and often of non-state agents. The functional capability and governance culture of participants in governance are also relevant to governance performance.

10 Further detail is contained in Martin (forthcoming 2015). 


\section{CONCEPTUAL AND METHODOLOGICAL CHALLENGES}

Major international environmental organisations are now signalling that significant improvements in the effectiveness of legal aspects of natural resource governance are essential. Their pronouncements indicate dissatisfaction with following the well-trod path of creating and interpreting international or intra-national legal instruments. The desire to focus far more upon effective implementation was signalled in the Rio+20 outcome document 'The Future We Want':11

19. We recognize that the twenty years since the Earth Summit in 1992 have seen uneven progress, including in sustainable development and poverty eradication. We emphasize the need to make progress in implementing previous commitments. We also recognize the need to accelerate progress in closing development gaps between developed and developing countries, and to seize and create opportunities to achieve sustainable development through economic growth and diversification, social development and environment protection. To this end, we underscore the continued need for an enabling environment at the national and international levels, as well as continued and strengthened international cooperation, particularly in the areas of finance, debt, trade and technology transfer, as mutually agreed, and innovation and entrepreneurship, capacity building, transparency and accountability. We recognize the diversification of actors and stakeholders engaged in the pursuit of sustainable development.

A parallel recognition that the focus of attention needs to turn from instruments to effective systems of governance has occurred within the IUCN with the emergence of the IUCN Natural Resource Governance Framework (NRGF). A key plank is a joint research program involving the World Commission on Environmental Law and the Environmental Law Centre in Bonn. ${ }^{12}$ The IUCN program is intended to generate methodologies, constituting a 'basket of governance tools'. These tools will include methods to objectively review and improve the quality of legal arrangements so as to support more effective and fair natural

11 UN General Assembly Resolution 66/288, adopted by the General Assembly on 27 July 2012.

12 The initial step being to develop and test a method for objective evaluation of the effectiveness of legal arrangements, in collaboration with teams from Australia, Brazil, China, South Africa and New Zealand. This work forms part of a broader CEESP-led initiative. 
resource governance. UNEP's Environmental Governance subprogramme, ${ }^{13}$ the Memorandum of Understanding signed between UNEP and the International Organization of Supreme Audit Institutions (INTOSAI - Working Group on Environmental Auditing, WGEA), and the comments of a number of scholars, all point in the same direction. Even as this chapter was being drafted, the Chief of Staff of the Organisation of American States Secretary General, in announcing a major initiative with the United Nations Environment Programme, said 'it is our hope that this agreement will contribute to addressing the greatest challenge of our century: implementation'. ${ }^{14}$

Martin and Craig's chapter, 'Accelerating the evolution of environmental law through continuous learning from applied experience', highlights the methodological challenges for the academic community in providing the knowledge needed to improve the applied effectiveness of environmental law, to help to form a more powerful, less cumbersome and fairer environmental governance regime. Whilst acknowledging legitimate critiques of environmental law scholarship, they reject the idea that embracing scientific empiricism will provide a strong basis for sufficient improvement. Recognising that engaging with axiological issues is essential to shaping environmental laws that reflect social values and concepts of justice, they explain why a rigidly deductive scientific paradigm cannot be directly transposed into legal research. However, disciplined continuous improvement based upon objective understanding of empirical phenomena, and rejection of subjectivity as the basis for investigations, are also essential to improving the effectiveness of environmental law. For these reasons the integrity of deductive reasoning based upon empirical evidence is also important in pursuing deeper insights into how to make the law work better. They suggest that a constructive approach is to acknowledge that applied legal research requires a strategic framework rather than either a philosophic or a scientific one. In seeking real-world improvements, one dimension is factual where deductive reasoning drawing on objective evidence is essential. However, since the goals of the law are heterogenous and

13 'To achieve their environmental commitments and goals, States need strong legislative, political and judicial systems. UNEP will use its expertise in environmental policy and law to help States further develop these institutions, and enhance their ability to effectively participate in international negotiations.' See United Nations Environment Program (2009).

14 OAS Secretary General Chief of Staff Hugo De Zela on the signing of the Agreement on Environmental Rule of Law and Sustainable Development, 19 November 2014, Washington D.C. 
dynamic, and the systems that produce outcomes are also multi-faceted and dynamic, it is not feasible to avoid the use of judgement in analysing applied legal arrangements and proposing improvements. As a result effective methods will have involved both objective and subjective elements, and the methods will have to be plural and pragmatic.

Xi, Ottinger, Robinson, Butzel, Wieder, Parker, Rucinski, Valova and Pianpian's chapter, 'Assessing environmental governance of the Hudson River Valley: application of an IPPEP Model', explores the nature of the politically dynamic relationship between the citizenry, elected officials, bureaucracy and the enterprise sector in shaping resource governance. They have used mathematical notation to emphasise the system interactions that occurred in a series of contests over resource use. The approach they use clearly points towards a methodology that focuses less upon the legal instruments that are involved in contests over governance, and far more upon the roles, institutions and political dynamics that enable legal tools to achieve socially valued outcomes. Their work highlights the significance of power as a feature of governance, suggesting the relevance of political theory to questions of legal natural resource governance. Whilst not explored in this chapter, the turbulent realpolitik that they document suggests that ideas from political economy, agency theories and other non-legal fields of investigation could fruitfully be used to build upon the dynamics that these authors have pointed towards.

Together these chapters point towards some insights about the methods that will be required for jurisprudence focused upon questions of effective implementation.

(1) Legal governance investigation is likely to be concerned with complex systems issues. This calls for a distinctive definition of scholarly issues and methods for investigation, but also points to the importance of fostering a rich relationship between doctrinal and philosophical jurisprudence.

(2) Research methods will need to enable a sophisticated understanding of political, legal, administrative, economic and social factors in determining what happens in practice. They will need to enable academic lawyers to understand more objectively and systematically the causes of environmental and social justice outcomes, so that they can propose more holistic strategies to improve effectiveness.

(3) The chapters suggest that methodological integrity in the research of effective systems of legal governance will draw upon the disciplines of empirical enquiry, but it is essential to avoid a 
misleading distinction between 'scientific' and 'dialogic' methods. Different elements of this jurisprudence will require the use of combinations of deductive and inductive reasoning and a variety of analytical approaches.

(4) These chapters direct our attention towards methodologies that are distinct from those other disciplines but which draw upon many fields of enquiry, which are uniquely legal and which can bring philosophic and pragmatic concerns together into new epistemological structures. Because the underlying questions are about practical improvements in effectiveness, and since a scientific approach depends upon explicit theory, the methods will need to deliver both abstract knowledge and clear practical recommendations, and they will need to support new methods for evaluation of the utility of both types of knowledge.

\section{INSTITUTIONAL ACCOUNTABILITY AND GOVERNANCE EFFECTIVENESS}

The three chapters that follow explore the links between institutional structure and accountability. They also reflect some of the observations from the first two chapters, including the necessity to consider the realpolitik of implementation, and the function of multiple actors serving different intersecting roles within a system of governance where legal instruments are central but not deterministic of outcomes. The authors draw our attention to the ways in which legal arrangements are embedded in political systems and highlight how this impacts on accountability of actors and organisations, and thus upon creating strong motivations for implementation and for continuing improvement in effectiveness.

In 'Putting the train of environmental protection on track: Nova Scotia's experiment in using legislation to strengthen environmental governance', Doelle and Lahey provide an encouraging indication that innovative legal arrangements can provide an effective accountability framework for the legal, political, economic and other aspects of the total governance system. They discuss how Nova Scotia's parliament has created political accountability for environmental and economic outcomes through the Environmental Goals and Sustainable Prosperity Act 2007. That legislation makes the performance of government agencies in pursuing sustainability and related economic goals transparent, and builds political accountability. The example points to the important links between political dynamics and legal arrangements, and suggests that innovation through the law can be a foundation for systemic improvements in 
natural resource governance. The role of innovations in law to provide a more firm basis for political accountability, and the law's capacity to catalyse strategies that go well beyond purely legal considerations, are areas of potential investigation and improved practice.

A less heartening illustration of the practical importance of the links between legal instruments, constitutional arrangements and political dynamics is provided by Gumley in 'Has environmental impact assessment (EIA) lost credibility? Recent concerns from Australia and Canada'. This chapter demonstrates that the effectiveness of implementation of ratified international agreements within a federated structure is subject to many structural and political variables that go beyond the instruments themselves. Institutional arrangements and structural variables can undermine (or bolster) the effectiveness of any legal instrument. His discussion of the effectiveness of Australian biodiversity conservation laws introduced pursuant to the Convention on Biological Diversity ${ }^{15}$ suggests that the lack of a strong framework for public accountability and transparency to supervise the performance of legal arrangements leaves it open for political actors to undermine the governance system. The example raises questions about the extent and ways in which political manipulation of 'non-law' factors (such as interstate administrative arrangements, budgets and internal management processes) can impact upon the effectiveness of legal arrangements and upon the rights of citizens. A deep comparative and historical analysis of the interactions between legal arrangements, bureaucratic structures and political dynamics would almost certainly reveal a number of ways in which the integrity and effectiveness of legal arrangements could be improved.

An aspect of the links between accountability and institutional structures is how the wording of legal instruments can radically alter the practical implementation of a broad legal principal. This issue is investigated by Lees in 'Contamination and the polluter pays principle'. She considers how the polluter pays principle has been legislated in Europe and the USA, leading to fundamentally different consequences in terms of accountability and remediation of pollution. In the version of the principle embodied in the US Environmental Protection Act 1990, a failure to trace the source of pollution to a particular polluter will result in an outcome of legal non-responsibility. Under these circumstances it is likely that either the general public or the environment will bear the harm. In the version used in the Environmental Protection Act 1990 the inability to trace specific causation results in the responsibility travelling

15 Entered into force, 29 December 1993. 
with ownership of the land, creating a strong 'stewardship' regime. A comparative law method that combines an investigation of different formulations of legal principles, the resultant allocations of risk accountability and the empirical consequences could provide important complementary insights to the doctrinal literature on regulatory design.

As was indicated by the preceding two chapters, embedded in structural considerations (such as the wording of legislation and the allocation of responsibility) are matters of distributive justice, as well as consequences for the protection and remediation of the environment. This indicates the importance of the links between the philosophical and the instrumental dimensions of governance, and matters of effectiveness in practice. Determining whether environmental law is effective or not implies an answer to the question 'effective in advancing what values?', and also that there be measures of the practical outcome of the application of the legal instrument. The combination of the philosophical and empirical questions points to the enormity of the task of objectively testing the effectiveness of legal principles, but it also points to why it is so important that this task be skilfully addressed.

It also highlights an important research issue. Economic concepts that have proven useful for the purpose of 'big picture' policy development may not transfer effectively into legal arrangements that are directly applied, and which have distributive (and therefore justice) effects. There has been negligible objective assessment in both law and economics of the 'meta-effectiveness' of economic instruments compared to regulatory or suasive approaches. Ex ante economic modelling cannot be considered to be as reliable as ex post empirical investigation. Examination of a particular instance cannot be considered to be the equivalent to a comprehensive investigation of the effectiveness of a variety of interventions under diverse circumstances. As with other effectiveness questions in environmental governance, objective findings would require consideration of what values are to be advanced, and what analysis (and therefore what data) would allow a meaningful answer to be given. However, the question is fundamentally important, because of the significant shift towards the use of economic instruments, supported by the implicit but empirically unproven view that the results of doing so are consistently more effective, efficient and fair than more traditional legal or social approaches.

Another area of legal governance where high expectations and achieved outcomes might be poorly aligned because of implementation issues is in public participation in environmental decision-making. The implementation challenges of public participation are carefully considered in 'Possible legal obligations to consult' by Howard and Teles Da 
Silva. The chapter indicates that the high expectations of what legal requirements for public participation can do to improve the performance of environmental governance are not likely to be consistently achieved unless implementation issues are addressed. The first challenge identified in the chapter is instrumental: many regulated requirements are poorly specified. They allow for enormous variation in the interpretation of the purposes of participation. They fail to directly engage with the degree of power transfer that is intended through the legal requirement. This leaves the advocates of potentially environmentally or socially harmful developments largely free to select an interpretation suitable to their interests. In consequence, they are able to select from a wide array of methods that in effect alter the practical effects of the legal requirement. It is also possible for incompetence to create distortions, even when implementation of the legal principles is not frustrated by self-interest. In the absence of effective accountability mechanisms (such as merits and process review), and given the frequency with which the public lacks standing or capacity to contest the processes that are used or the outcomes of these processes, it ought not be surprising that the implementation of public participation principles is highly variable. The authors consider the situation in two 'non-Aarhus' jurisdictions, which confirm the significance of the challenges that they have identified. ${ }^{16}$ If aspirations of legal requirements for public participation in natural resource governance are to be reliably satisfied, then it is likely that a more comprehensive approach to the integrity of implementation will be needed. Also, given that the purpose of many of these requirements is to protect the interests of the less powerful there is a strong social justice rationale for lawyers to pursue this empirical as well as philosophical investigation and to promote integrity mechanisms for public participation that will work reliably in practice.

16 The United Nations Economic Commission for Europe (UNECE) Convention on Access to Information, Public Participation in Decision Making and Access to Justice in Environmental Matters (the 'Aarhus Convention') 2001. This convention seeks to implement Principle 10 of the Rio Declaration by granting to the public rights to information, participation and access to justice in environmental decision-making processes. For further discussion of the Aarhus Convention, refer to: Lee and Abbot (2003); Hartley and Wood (2005); Kravchenko (2007); Toth (2010). 


\section{WHAT DETERMINES THE EFFECTIVENESS OF INTERNATIONAL REGIMES?}

Aspects of the four chapters we have just considered, which focus upon intra-national implementation of environmental governance regimes, are reinforced in the next four chapters where the concerns are bilateral and multilateral international regimes. As with the intra-national implementation of environmental law, issues of instrumental design, constitutional structures, power and politics all feature as matters impacting upon effectiveness.

In 'Implementing international water agreements', Rieu-Clarke and Gooch focus upon implementation of transboundary water governance. Their chapter begs the questions: "what influences the implementation of transboundary agreements?' and 'what strategies are most likely to make such arrangements effective?' They argue that implementation could be considered at a procedural or substantive level. They highlight the difference between legal, behavioural, and problem solving effectiveness in international regimes. In considering effectiveness they point to the distinction between a political realist perspective (concerning imbalances in power relationships), or an interpretation of the dynamics as a 'collective action' problem. This interpretation of transboundary water management is mirrored in Owino's analysis of transboundary management of Lake Victoria ('Fouling Adam's Eden: a legal analysis of the collective action challenge in Lake Victoria'). In both cases the role of legal arrangements in determining applied outcomes is analysed within the context of political and power relationships. The effectiveness of instruments is largely seen as being determined by their 'fit' with economic and political (or in some instances military) contexts. In both instances the significance of the organisational structures and political and economic relationships that contextualise legal arrangements cannot be overstated.

These chapters support a view that understanding the effectiveness of a legal instrument requires an understanding of the extent to which its requirements respond to the degree of behaviour change that is needed. They also suggest that whilst procedural obligations are important, if the economic and political status quo runs strongly counter to the policy objectives then legal obligations that are specific are likely to be required. In this regard there is a resonance with Doelle and Lahey's example, which also indicates the importance of specificity and transparent evaluation of commitments. A research-based understanding of the problem of proportionality of the legal instrument to the challenge to be met could 
help reduce the tendency for political adoption of legal arrangements that are unlikely to work.

The chapters from Rieu-Clarke and Gooch, and Owino, point to the practical importance of the capacity of states to implement the commitments that they make. This is mirrored in other chapters, where the concern is not nation states but citizen capacity to do what is expected of them from the legal instrument. Below we refer to a model of behaviour where capacity is identified as one of the three fundamentals (alongside motivation and opportunity) governing environmental and pro-social behaviour of citizens. Regulatory process design is another area where there are significant opportunities for well-researched improvements, which would be likely to improve the overall effectiveness of natural resource governance.

Rose's chapter, 'Marine protection treaties in Antarctic Waters: fragmentation or coordination in international treaty implementation', directs our attention to the architecture of a variety of legal instruments that interact to constitute a framework for marine environmental governance. An issue that this chapter canvasses is the effect of complexity of legal architectures, due to the proliferation of legal instruments and implementation structures. The potential for competing norms, high transaction costs and resulting inefficiency or ineffectiveness is brought into focus. Rose highlights the co-existence of five distinct normative frameworks that intersect in the management of the Antarctic marine environment. These norms are translated into a dazzling array of instruments, with inconsistencies in their implementation and interpretation. To point this confusing situation out is not to suggest that the creation of these instruments is misguided. Rather, it focuses our attention upon the challenges of accountability and the transaction costs of implementation that arise in such situations, which are more common than not (as is pointed out in the later chapter by Martin and Noble). To minimise transaction cost and accountability failures, coordination regimes have been created, which include resource sharing through joint secretariats as well as information management. This points to the potential for bureaucratic innovation to improve effective implementation, even if architectural redesign is not feasible politically. Given the continuing chorus of criticism of environmental instruments as 'green tape' by the business sector, exploration of ways to reduce complexity and transaction costs whilst not derogating from substantive principles for environment protection would seem to be a fruitful pursuit.

De Cendra's chapter 'The effectiveness of instrument mixes in environmental law: insights from ship-source pollution' reflects the systems 
nature of implementation, and points explicitly to the behavioural dimension of legal governance. This chapter indicates a sound behavioural principle that the decisions that people take and the effectiveness of their actions are substantially determined by social and institutional contexts. This points to the need for analytic structures that can allow legal scholars and practitioners to better understand and take into account contexts in developing legal strategies. The chapter highlights the potential for an explicitly behaviouralist approach to the design and implementation of legal arrangements. ${ }^{17}$ De Cendra analysis in effect considers the performance of a 'cocktail' of regulatory and market arrangements, which together should create a motivational framework of carrots and sticks. He considers how these arrangements in combination make it possible and relatively attractive for the potential wrongdoer to avoid the risks of penalty for unlawful discharges. Since the purposes of environmental governance are behavioural, an explicitly behaviouralist analysis of the role and function of environmental law alongside economic, social and other forms of intervention is appealing. There are signs of a fledgling suite of theories within the legal academic community that can help to 'plug' this jurisprudential gap. Other legal scholars have proposed concepts like 'smart regulation' and 'responsive governance', as well as various new forms of governance. ${ }^{18}$ These emphasise different concepts that could together constitute an integrated framework for the design and testing of behavioural interventions, and suggest that the effectiveness of governance arrangements could be improved by harnessing different types of intervention arrayed systematically. ${ }^{19}$ Other disciplines suggest the potential to facilitate a move by legal scholars into behavioural systems thinking. An example is from the recent publication The behaviour change wheel: A new method for characterising and designing behaviour change interventions. ${ }^{20}$ That research draws on a meta-analysis of behaviouralist literatures and suggests the potential for an integrative framework for exploring how behavioural science, economics and legal governance systems might be drawn together in a coherent manner. It also highlights the intrinsically multi-disciplinary investigations that are likely to be needed in the pursuit of more behaviourally effective environmental laws. This is just one

\footnotetext{
17 See Kennedy (2010).

18 Gunningham, Grabosky and Sinclair (1998); Baldwin and Black (2008).

19 Noting that the systemic, multi-intervention approach proposed by such legal scholars does not fit well with the economic theory that a single intervention should be used for a single purpose.

20 Michie, Stralen and West (2011).
} 
illustration that there is a rich crop of behaviouralist insights that could be harvested and applied in the service of more effective environmental laws. ${ }^{21}$

\section{A FUTURE WORLD OF NETWORKED GOVERNANCE?}

The final four chapters explore the increasing 'hybridity' of natural resource governance. Modern environmental governance involves many actors with different but intersecting roles. These include government organisations, private market certification schemes, traders in environmental services, corporations with internal and value chain environmental management systems, civil society activists, and consumers exercising their choice to 'buy green'. Together they constitute a system that combines economic, social and legal systems with the drivers of the behaviour of citizens and their organisations to change environmental and social outcomes. Non-government organisations like corporations and civil society groups are pivotal to the effectiveness of natural resource governance. The power of the marketplace and the political establishment, as well as social institutions (including religious and cultural organisations), in shaping how resources are conserved and used, surely cannot be discounted. This suggests that for contemporary environmental lawyers to focus heavily upon traditional regulatory arrangements and the functions of government, when so much 'real world' natural resource use and conservation behaviour is driven by private actors and by nonregulatory instruments, may be an unrealistic treatment of the realities of natural resource governance. These chapters highlight the hidden contest between government and private actors (commercial and citizen) over who will govern for the environment, and what instruments and strategies will prevail. They also reinforce the relevance of issues addressed in earlier chapters, including the need to reduce the counterproductive impacts of fragmentation and transaction costs, the importance of issues of capacity (including regulator capacity) and the need to focus upon improving the performance of an institutional system, rather than improving only the performance of a legal instrument.

The chapters by Holley and Lawson, 'Implementing environmental law and collaborative governance', and Paddock and Masterton, 'Private

21 Garmestani (2014); Martin, Williams and Kennedy (2012); Kennedy (2010); Kennedy and Phromlah (2011). 
environmental enforcement: using supply chain requirements to help assure better environmental outcomes', are complementary explorations of the increasingly important role of the private sector in regulation of environmental stewardship. Holley and Lawson point out that there are many situations where reliance upon central (government) action is likely to be sub-optimal because of limits to knowledge and authority, and because of the high transaction costs and barriers to effective supervision. Under such circumstances it is likely that decentralised mechanisms will be required. Environmental management issues such as diffuse source pollution, the management of rural and remote landscapes, or the harvesting of fugitive environmental resources such as fish demonstrate the transaction cost limits to traditional regulation, as well as limits to many types of economic incentives. Under such situations collaborative governance in its many different forms can be an efficient and effective alternative (or complement) to traditional approaches. Holley and Lawson use their empirical investigations to draw conclusions about when, where, and how such arrangements might create more effective public policy outcomes. They also point out opportunities for research to inform governance practice. A consideration they highlight is the behavioural power of self-standards, compared to externally imposed standards, due to psychological factors - this harks back to our earlier discussion of the potential for behavioural science to inform improved effectiveness of legal governance. They indicate that self-standards may motivate improvements that go beyond mere compliance with regulation. Their analysis is, however, also realistic in suggesting the limits to voluntary schemes, in particular the dangers of a lack of external supervision and accountability for the performance of industry self-standards. This is consistent with our observation that innovative approaches to natural resource governance, no matter what their form, are likely to require sound integrity mechanisms. A traditional function of government is to ensure that the instruments which are ratified for use are credible, by providing effective supervision and transparent reporting. The tradition of government oversight of private stock markets points to the potential for 'self-regulation' to be distinguished from 'non-regulation' through the use of government mandates, independent oversight and strongly enforced conditions to ensure integrity. The authors give examples of where governance collaboration is backed by government integrity mechanisms.

Paddock and Masterton identify that modern industry often involves complex multilevel international supply chains largely beyond the reach of national environmental laws. They highlight that private regulation and enforcement of private rules within supply chains are for this reason increasingly important mechanisms of governance. Martin and Noble, in 
'Hybrid governance and "wicked" natural resource risks', independently consider similar issues but with a different orientation. Both chapters highlight the diverse drivers for private or self-regulation, and suggest that these often reflect far more pragmatic and more powerful drivers than 'mere' ethical concerns. Paddock and Masterton draw particular attention to the value of corporate reputation and risks to the social licence of the firm. Martin and Noble expand these drivers to include other economic and risk variables, and highlight how these diverse motivations tie into various aspects of corporate strategy and affect different functions and roles within a modern corporation. Paddock and Masterton provide a taxonomy of 'green' supply chain initiatives including certification and audit mechanisms, supply chain contracts, transparency mechanisms and closed loop approaches which strengthen disclosure. They also point to the role of information mechanisms such as life-cycle analysis as being increasingly important within the 'selfregulatory' arrangements of sophisticated industrial systems. Within this collaborative governance perspective on industry value chains the roles of government include facilitation, coordination, information dissemination and the use of purchasing power as an incentive for more effective self-governance. They point to the potential for a deeper relationship between government and industry, based upon a strategic response to the overall potential of industry supply chain stewardship structures, rather than the current largely $a d$ hoc and tactical response to individual schemes.

This perspective echoes the arguments by Martin and Noble, who consider what is required to govern the increasingly vicious problem of complex trans-national risk. Based upon the history of environmental law, they explain that contemporary challenges are very different from the types of issue that were the focus of attention in the 1970s when an explosion in environmental law instruments was triggered. Contemporary (and future) legal governance will not only have to deal with the conventional type of issue where cause and effect are observable, and where governments have the jurisdictional rights and the institutional capacity to intervene effectively. It will also have to cope with complex system issues, notably new types of risk, where cause and effect transcend nation state jurisdictions and where the agencies of government are not likely to have sufficient technical knowledge (let alone authority and resources) to respond effectively. They point out that risk management concerns are not limited to risks from and to the environment. Public policy is also a high-risk venture, with failures in the form of non-adoption, ineffective design or execution or undesirable spillovers being frequent. There is a shared interest between government, industry 
and civil society to create policy solutions that are reliable politically, operationally and in terms of the fair distribution of costs and benefits. Martin and Noble propose an innovative partnership to integrate the capacity of the public and the private sector to respond to environmental (and social) risks. Crafting new governance relationships and making them work requires detailed investigation and careful negotiation, but could lead to more effective regimes. However, it is also possible that collaborations could result in weakened governance. Strategic hybridity and the supervision of the operation of innovative hybrids to ensure that they are effective is a scholarly topic that justifies more careful investigation.

The final chapter by Pink and Bartel, 'Regulators networks: collaborative agency approaches to the implementation and enforcement of environmental law', highlights a different aspect of collaborative governance: the potential of networks of regulators as a response to the need to accelerate learning to cope with regulatory complexity and coordination problems. As highlighted in previous chapters, contemporary natural resource regulation issues can be far more complex than those traditionally considered. The instruments and the implementation requirements are often diverse, and the resources available will generally not increase to reflect the increasing difficulty of regulation. Pink and Bartel highlight that traditional 'silos' of expertise may not cope effectively with the new types of natural resources governance challenges, particularly if the teams are small, isolated and under-resourced. As was also indicated by Martin and Noble, one way of responding is to pool knowledge and resources.

Pink and Bartel highlight that even within the regulatory sector, strategic alliances to tackle common interest problems are being used increasingly to improve the effectiveness of natural resource governance. They point to the need for governance systems to develop knowledge and other capabilities far more rapidly than they have typically had to in the past, so that they can cope with the accelerating changes in the legal, political and other context within which they must work. Their chapter provides information on different forms of hybrid structure and the variety of alternative strategies and network operations that are possible. The ideas they develop are rooted in a behavioural awareness of the effects of human and organisational capacity upon the performance of systems of governance. This links back to earlier observations about the desirability of developing a better structured and more comprehensive approach to understanding what capabilities of what people and organisations are needed to ensure effectiveness, and the development of more 
comprehensive institutional approaches to embed required capacity at the same time as creating new legal instruments.

\section{SYNTHESIS AND POTENTIAL SCHOLARLY DIRECTIONS}

Of course, it is not possible in this overview to do justice to the richness of the work of the authors whose chapters are featured. We have attempted to show that these diverse perspectives are all linked into a single topic: the scholarship that is needed to improve the applied effectiveness of legal arrangements for environmental governance. If indeed, as Hugo De Zela stated so clearly, implementation of legal instruments is the greatest governance challenge of this century, ${ }^{22}$ then it justifies a concentrated and significant scholarly endeavour. It has been the purpose of this book to try to bring implementation issues to the forefront and to identify some of the dimensions of the jurisprudence that will be required to contribute to this worthy aim.

The chapters in this book demonstrate that a jurisprudence of environmental law implementation will be very different from the jurisprudence of legal philosophy, or of legal instruments. It will necessarily focus upon legal issues within the context of broader systems, and the contexts, that shape the outcomes of environment law interventions. It will also need to consider ways of combining different types of legal, economic, social and behavioural interventions into more effective 'cocktails', and paying attention to demonstrable results in terms of environmental protection, social justice, and economic efficiency.

The authors represented in this book have considered examples from many different countries and have focused upon a variety of environmental and governance issues. Their analyses suggest that there are many different ways to improve the effectiveness of legal arrangements to govern the environment. They have also pointed to the need to draw from a number of other disciplines, but to integrate these diverse methods into approaches that are well-designed to meet the needs of environmental law scholarship.

There are other dimensions to the implementation task that we have not considered, simply because of limits to space. Many of these are touched upon in environmental law publications, but they have not

22 Organization of American States (2014). 
generally been brought together as aspects of a coordinated jurisprudential field. Some of these include issues of judicial and legal culture and capacity; natural resource conflicts; indigenous peoples perspectives and governance frameworks; the effects of constitutional frameworks; and many others.

Environmental law is a form of behavioural management where society pursues continuous improvement. However, environmental law scholars do not draw upon a widely shared theory about what works and what does not, and do not have the types of institutional processes of peer review and joint theorising that are fundamental to scientific improvement. Faced with an array of issues, opportunities and epistemological choices there is a risk that investigations into effectiveness will become diffused and lose their focus and effectiveness. Indeed, we suggest that this is the current state of these enquiries within the environmental law academic community. We argue that it is essential: if the environmental law community is to rise to the challenge of improving the tangible effectiveness of legal arrangements for natural resource governance, then it will need a co-ordinated and powerful approach to investigating these diverse issues.

In many ways the timing could not be better for the creation of a distinct specialist jurisprudence of implementation of environmental law. A number of the most important international agencies have identified that it is essential that this challenge be met. The next challenge is to exploit this unique moment in time to create a concentrated and disciplined program of collegial investigation.

Finally, the editors wish to thank the Secretariat, the Research Committee and the Governing Board of the IUCN Academy of Environmental Law whose willingness to host a workshop on implementation of environmental law made it possible to advance this book far more efficiently than otherwise would have been possible. We would also like to thank Amy Cosby and Matthew Ryan, our editorial assistants. Finally, the editors would like to thank the New Zealand Law Foundation for their generous grant funding in support of the 2013 IUCN Academy of Environmental Law Colloquium held in Waikato. That support also contributed materially to the development of this book.

\section{REFERENCES}

Ashley D. and D. Orenstein (2005), Sociological Theory: Classical Statements (6th edn, London: Pearson Education). 
Baber, W. and R. Bartlett (2009), Global Democracy and Sustainable jurisprudence: Deliberative Environmental Law (Cambridge, MA: MIT Press).

Baldwin, R. and J. Black (2008), 'Really Responsive Regulation' 71(1) Modern Law Review 59-94.

Burdon, P. (ed.) (2012), Exploring Wild Law: The Philosophy of Earth Jurisprudence (Adelaide: Wakefield Press).

Garmestani, A. et al. (2014), 'The Integration of Social-Ecological Resilience and Law in Garmestani, A. and C. Allen (eds) (2014) Social-Ecological Resilience and Law (New York: Columbia University Press).

Gunningham, N., P. Grabosky and D. Sinclair (1998), Smart Regulation: Designing Environmental Policy (Oxford: Clarendon Press).

Hartley, N. and C. Wood (2005), 'Public Participation in Environmental Impact Assessment - Implementing the Aarhus Convention' 25(4) Environmental Impact Assessment Review 319-40.

Kennedy, A. (2010), 'Using Community-Based Social Marketing Techniques to Enhance Environmental Regulation' 2(4) Sustainability 1138-60.

Kennedy, A. and W. Phromlah (2011), 'Behavioural Strategies to Support Climate Change Resilience' 10 Environmental Taxation and Climate Change: Achieving Environmental Sustainability through Fiscal Policy 79.

Kravchenko, S. (2007), 'The Aarhus Convention and Innovations in Compliance with Multilateral Environmental Agreements' 18 Colorado Journal of International Environmental Law and Policy 1.

Kuper, A. and J. Kuper (1996), The Social Science Encyclopedia (Abingdon: Taylor \& Francis).

Lazarus, R. (1996), The Making of Environmental Law (Chicago: University of Chicago Press).

Lee, M. and C. Abbot (2003), 'The Usual Suspects? Public Participation under the Aarhus Convention' 66(1) Modern Law Review 80-108.

Loasby, B. (2002), Knowledge, Institutions and Evolution in Economics (Abingdon: Psychology Press).

Luhmann, N. (1995), Social Systems (Redwood City, CA: Stanford University Press).

Martin, P., J. Williams and A. Kennedy (2012), 'Creating Next Generation Rural Landscape Governance: The Challenge for Environmental Law Scholarship' in P. Martin et al. (eds) Environmental Governance and Sustainability (Cheltenham, UK and Northampton, MA, USA: Edward Elgar) 46-80.

Martin, P. et al.(forthcoming, 2015), Developing a Structure for a Legal Component for the IUCN Natural Resource Governance Framework (IUCN Environmental Law Centre and the World Commission on Environmental Law forming part of an IUCN ELC legal governance evaluation report).

Michie, S., M. van Stralen and R. West (2011), 'The Behaviour Change Wheel: A New Method for Characterising and Designing Behaviour Change Interventions' 6(1) Implementation Science 42.

Nobelprize.org, 'Linus Pauling - Facts' (Nobel Media AB, 2014) accessed 28 March 2015 at http://www.nobelprize.org/nobel_prizes/chemistry/laureates/1954/paulingfacts.html.

Organization of American States (2014), Press Release: OAS and UNEP Sign Agreement on Environmental Rule of Law and Sustainable Development (Organization of American States, 19 November) accessed 28 March 2015 at http:// www.oas.org/en/media_center/press_release.asp?sCodigo=E-506/14. 
Pūraitè, A. (2012), 'Origins of Environmental Regulation' 19(2) Jurisprudence 657-74.

Riddell, A. (2014), Human Rights and the Environment (Abingdon: Routledge Handbook of Environment and Society in Asia).

Schaller, R. (1997), 'Moore's Law: Past, Present and Future' 34(6) Spectrum, IEEE 52-9.

Schultz, D. and S. Schultz (2011), A History of Modern Psychology (Independence, KY: Cengage Learning).

Solomon, R. and K. Higgins (1996), A Short History of Philosophy (Oxford: Oxford University Press).

Tarlock, A.D. (2010), 'Environmental Law: Then and Now' 32 Washington University Journal of Law and Policy 1.

Tarlock, A.D. (2003), 'Is There a There in Environmental Law?' 19 Journal of Land Use and Environmental Law 213.

Teece, D. (1986), 'Profiting from Technological Innovation: Implications for Integration, Collaboration, Licensing and Public Policy' 15(6) Research Policy 285-305.

Toth, B. (2010), 'Public Participation and Democracy in Practice - Aarhus Convention Principles as Democratic Institution Building in the Developing World' 30 J. Land Resources \& Envtl. L. 295.

United Nations Environment Program, Environmental Governance (2009), accessed 28 March 2015 at http://www.unep.org/pdf/brochures/EnvironmentalGovernance. pdf.

Westbrook, D. (1993), 'A Liberal Environmental Jurisprudence' 27 UC Davis Law Review 619.

Winter, G. (1989), 'Perspectives for Environmental Law - Entering the Fourth Phase' 1 Journal of Environmental Law 38. 
Paul Martin and Amanda Kennedy - 9781783479313 Downloaded from PubFactory at 04/26/2023 01:22:13PM via free access 